\title{
Ultrastructural study of the host-parasite interface after infection of two species of teleosts by Labratrema minimus metacercariae (Trematoda, Bucephalidae)
}

\author{
Elisabeth Faliex \\ Marine Biology Laboratory, University of Perpignan, 52 Av. de Villeneuve, F-66860 Perpignan Cedex, France
}

\begin{abstract}
A histo-cytological study was carried out on the effects of Labratrema minimus (Stossich, 1887) metacercariae (Trematoda, Bucephalidae) in the liver of the second intermediate hosts, grey mullet Liza ramada and silverside Atherina boyeri. The following features were seen at the interface between the fish and the parasite. (1) Formation of the initial layer constituting the cyst wall derived from the parasite and of the middle and outer layers, forming the capsular-like coat derived from the host liver. The hepatic origin of the latter 2 layers protects the parasite against a possible inflammatory reaction from the host, both in grey mullet and silverside. (2) Development of the 3 layers, defining both the cyst wall (initial) and the capsular-like coat (middle, outer), as a dynamic zone from the beginning of encystment until the seventh month after infection of juvenile grey mullet. (3) Accumulation of voluminous lipid droplets at an early stage ( $3 \mathrm{~d}$ post-infection) both in the metacercarial tegument and in the cyst cavity, and of a few such droplets within the cyst wall. (4) High level of infection and presence in the same parenchyma of various developmental stages of Labratrema minimus metacercariae, demonstrating that in the lagoons the silverside is subject to multiple successive infections.
\end{abstract}

\section{INTRODUCTION}

Larval distomatoses occur commonly and their study is of great interest because of the pathogenicity induced at the metacercarial stage in many teleosts, which are the second intermediate hosts in the life cycle of these trematodes. A high level of metacercarial infections in these second intermediate hosts is commonly observed, and this can lead to death in some cases. Baturo (1978) showed a positive correlation between fish size and the lethal number of infecting cercariae. Thus, only one metacercaria of Acanthostomum (Molin, 1859) can rapidly induce death in the young stages of sea bream (Maillard et al. 1980). Wallet (1984) demonstrated that in freshwater, cercariae of Bucephalus polymorphus (Baer, 1827) (Trematoda, Bucephalidae) constitute very pathogenic agents for cyprinid fingerlings.

According to Jourdane (1975) and Maillard (1976), lagoons (Gulf of Lion, Mediterranean Sea) constitute exclusive and privileged places for marine fish tre- matodes, in that life cycles of most trematodes occur only in lagoons and host-parasite encounter is easy in such small places. Among them the metacercarial stage of Labratrema minimus (Stossich, 1887) (Trematoda, Bucephalidae) is one of the most frequent and widespread.

According to Maillard (1976), the adults of Labratrema minimus found in the intestine of Dicentrarchus labrax (Linnaeus, 1758) (definitive host) produce eggs which are evacuated in the vicinity of the first intermediate host, Cerastoderma glaucum (Bruguiere, 1789) (Mollusca). These are infected by miracidia and release many asexually formed cercariae. The cercariae penetrate into various small teleosts such as silverside, grey mullet, or sea bream (second intermediate hosts) during summer and encyst as metacercariae. The adult stage of the parasite is reached when young teleosts infected by $L$. minimus metacercariae are eaten by the definitive host.

Metacercariae of Labratrema minimus encyst preferentially in the liver of young teleosts. A very high level 
of metacercarial infection (prevalence $=100 \%$, intensity $=47.3$ ) was reported in silverside Atherina boyeri (Risso, 1810) for the first time by Faliex (1984). The accumulation of these metacercariae in grey mullet induces severe hepatic alterations (Biagianti \& Maillard 1986) which can lead to death (Maillard 1976). However, Faliex \& Biagianti (1987) reported that hepatic changes are less dramatic in naturally infected silverside

This work analyses the cytological modifications observed in the liver of the second intermediate host following penetration of cercariae. This interface area has been studied in experimentally infected grey mullet Liza ramada (Risso, 1826) and in naturally infected silverside Atherina boyeri. These 2 species of teleosts are good mâteriál fur hisio-cyiolugical stuảy because of their frequency and their abundance in the Mediterranean lagoons. Moreover, uninfected juvenile grey mullet were easily collected as they entered lagoons and easily kept in the laboratory. Experimental infections permitted identification of sequential events of ultrastructural hepatic disturbances related to the encystment phase and the maintenance of the parasite in the host organ. In contrast, silverside cannot be kept in the laboratory. Therefore, the present work is a comparative analysis of the effect of Labratrema minimus metacercaria in the liver of experimentally infected grey mullet $L$. ramada and naturally infected silverside A. boyeri.

\section{MATERIALS AND METHODS}

Fifty-two uninfected juvenile Liza ramada (from 29 to $43 \mathrm{~mm}$ Total Length) were caught in April, while entering Leucate lagoon (northwest Mediterranean Sea), and kept in captivity in the laboratory. Six months later, each fish, among 42 fish studied (salinity $=27 \%$ ), was experimentally infected for $1 \mathrm{~h}$ with 25 cercariae of Labratrema minimus from Cerastoderma glaucum. Ten specimens were used as control fish. Samples were examined until the 8th month post experimental infection. Naturally infected Atherina boyeri were caught in Lapalme lagoon.

Fishes were killed by decapitation and immediately afterwards, pieces of liver from Atherina boyeri and Liza ramada containing metacercariae of Labratrema minimus were fixed in Bouin Holland's solution and embedded in paraffin. Samples were sectioned at $7 \mu \mathrm{m}$ and stained with nuclear fast red/picro-indigo carmine. In a similar way, pieces for electron microscopy were fixed in $3 \%$ glutaraldehyde buffered with $0.1 \mathrm{M}$ sodium cacodylate, pH 7.4 at $4{ }^{\circ} \mathrm{C}$ for 4 h. Samples were post-fixed in $2 \% \mathrm{OsO}_{4}$ in the same buffer and, after dehydration in a graded acetone series, were embedded in Epon (Brusie 1983). Semithın sections $(1 \mu \mathrm{m})$ were stained according to Richardson et al. (1960) and ultrathin sections according to Reynolds (1963).

\section{RESULTS}

\section{Experimental infections of Liza ramada juveniles}

The Liza ramada juveniles used in this study suffered from moderate infection similar to that observed in wild samples. The liver of grey mullet from natural lagoons had a low level of metacercarial infection (Faliex unpubl.: from 1 to 6 metacercariae per fish). Six major stages were selected: $1 \mathrm{~d}, 3 \mathrm{~d}, 15 \mathrm{~d}, 2 \mathrm{mo}, 4 \mathrm{mo}$, and 7 mo post experimental infection.

One day post infection (Fig. 1). When the parasite enters the liver, the first stage of the encystment phase is the formation of an initial layer, composed of very small granules scattered along the liver cells. In the parasite tegument some lipid droplets are observable. Between the parasite and the initial layer, there is a cyst cavity and on the other side of the layer are electron-dense hepatocytes which become flattened as a result of compression of the parasite. These hepato-

Figs. 1 to 4. Liza ramada experimentally infected with Labratrema minimus. Light and electron micrographs of the liver of $L$. ramada. Fig. 1. One day post infection: setting up of the initial layer (il), first stage of the encystement phase of $L$. minimus. In the metacercarial tegument ( $\mathrm{Te}$ ) some lipid droplets (L) can be observed. Note the presence of flattened hepatocytes (H) containing some lipid droplets (L), mitochondria with dense matrix (M) and residual bodies (Rb). Some of them show swollen mitochondria $(*) .(\times 4500)$. Fig. 2. Three days post infection. (a) Accumulation of voluminous lipid droplets (L) in the metacercarial tegument (Te). Note the presence of lipidic material (L) in the cyst cavity (Cc). ( $\times 5000)$. (b) Presence of lipid droplets (L), few in number, within (arrow) the initial layer (il), ( $\times 7500)$. Figs. $3 \& 4$. Fifteen days post infection. Fig. 3. Semithin section, Richardson stained. Light micrograph showing L. minimus metacercaria (Met) and the initial layer (il) in the hepatic parenchyma (HP). ( $\times 512)$. Fig. 4 . Thickening of the cyst wall (Cw) by addition of granular material ( $\mathrm{gm}$ ) located in the cyst cavity (Cc). Note the presence of 2 new layers constituting the capsular-like coat. A middle layer $(\mathrm{ml})$ made up of degenerating $(\mathrm{DH})$ and necrosed hepatocytes (NH) and an outer layer (ol) formed by flattened hepatocytes and some fibroblasts (Fi). $(\times 4500)$

Abbreviations used in figures. $\mathrm{Cc}$ : cyst cavity; cf: collagenous fibres; $\mathrm{Cw}$ : cyst wall; $\mathrm{D}$ : desmosomes; $\mathrm{DH}$ : degenerating hepatocyte; Fi: fibroblast; gm: granular material; H: hepatocyte; HP: hepatic parenchyma; il: initial layer; L: lipid droplet; la: lysed area; Iz: loose zone; M: mitochondria; Met: metacercaria; ml: middle layer; Nc: necrosed cells; NH: necrosed hepatocyte; ol: outer layer; pz: penetration zone; $\mathrm{Rb}$ : residual body; Te: tegument; $\mathrm{V}$; vacuole 

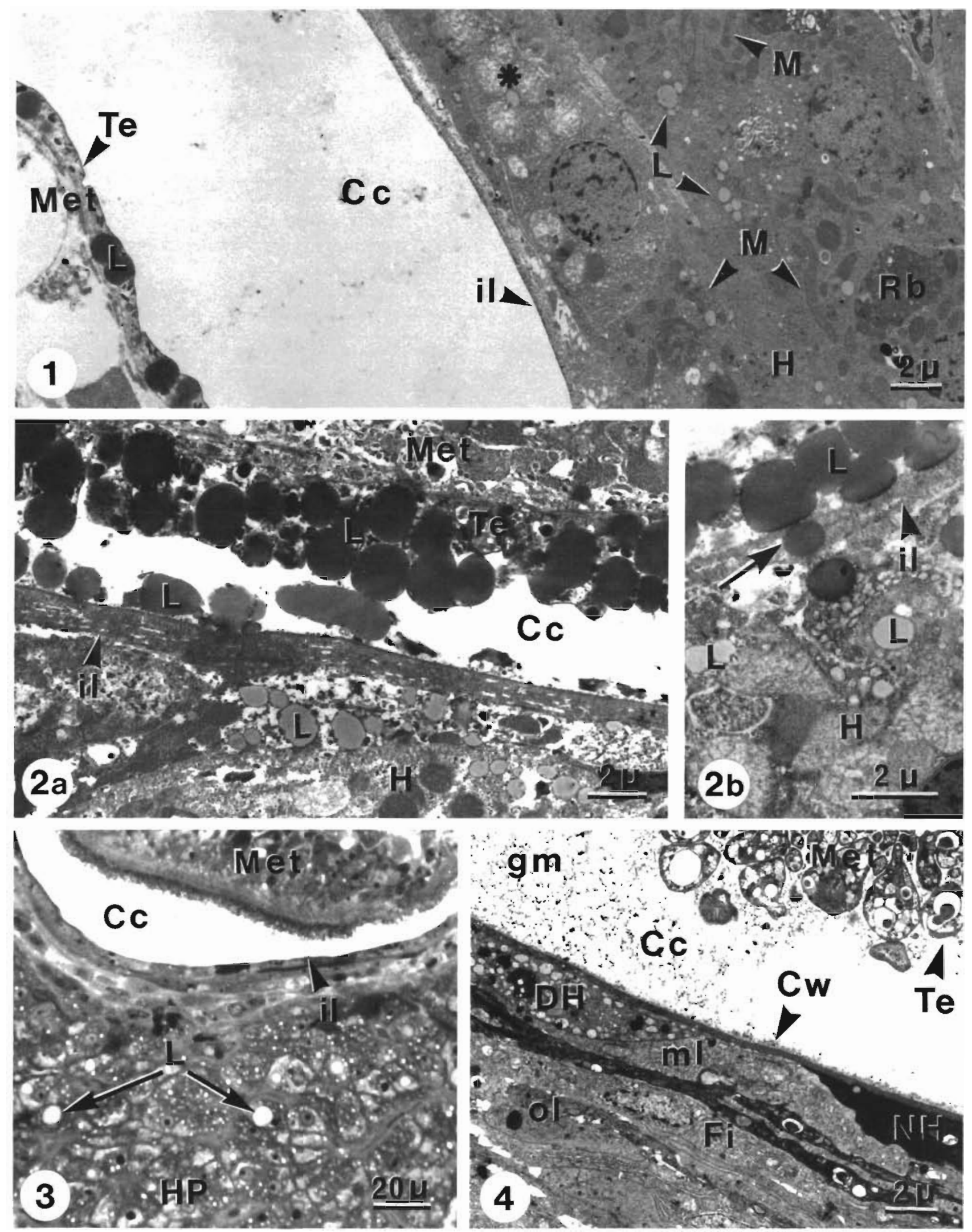
cytes contain some lipid droplets, mitochondria with dense matrix, and some residual bodies. Some of them show disturbances such as swollen mitochondria with a clear matrix.

Three days post infection (Fig. 2a, b). The granular material is becoming more abundant and lipid droplets are still observable in underlying hepatocytes, but the most important feature is the increase in number and size of lipid droplets in the metacercarial tegument and the presence of lipidic material in the cyst cavity (Fig. $2 \mathrm{a}$ ). In addition, lipid droplets may be detected located within the initial layer (Fig. 2b).

Fifteen days post infection (Figs. $3 \& 4$ ). Viewed by light microscopy, the hepatocytes directly adjacent to the parasite are flattened, whereas the furthest ones are very slightly flattened and contain a few lipid droplets. The initial layer is also clearly discernible (Fig. 3). At the electron microscope level, a fine granular material, located in the cyst cavity between the parasite and the liver, contributes to thickening the initial layer which is more compacted than in the previous stages and is now called cyst wall.

At this stage, 2 new layers can be observed. The hepatocytes disrupted during the penetration of the cercaria into the liver, which show important degenerative processes, constitute the middle layer, directly adjacent to the cyst wall. Underlying hepatocytes which are less damaged than the preceding ones and slightly flattened compose the outer layer. These layers are referred to as middle and outer, respectively, owing to their position relative to the cyst wall, and together constitute the capsular-like coat.

No further lipid droplets can be observed either in the metacercarial tegument or in the cyst cavity.

Two months post infection (Fig. 5). At this stage, the middle and the outer layers of the capsular-like coat are thickened by addition of new hepatocytes. Hepatic cells of the middle layer are degenerative and necrosed as previously described, whereas those of the outer layer are now very flattened, and linked by numerous desmosomes. Membrane organelles and nuclei are often missing.

A loose zone clearly separates the outer layer from the underlying hepatocytes which are slightly compacted and flattened.

Four months post infection (Figs. 6 \& 7). Granular material in the cyst cavity is still detectable. The 3 layers previously recognized belonging respectively to the cyst wall (initial) and the capsular-like coat (middle, outer) are now clearly separate and fully developed. The cyst wall is thicker than in the previous stages and is divided into 2 sublayers. The first one, close to the cyst cavity, has a low electron density and irregular outlines while the second one is more electron-dense than it was when originally released. The middle layer of the capsular-like coat has an irregular organization ranging from a region of vacuoles formed by lysed hepatocytes to a very electron-dense area formed by necrosed hepatocytes. In the latter case, the degenerative processes are so advanced that the hepatocytes are devoid of discernible cellular structures. The outer layer shows the same pattern as described in the previous stage. Here and there, some elongated fibroblasts can be seen. The underlying hepatocytes, clearly separated by a loose zone, now show a normal shape.

Seven months post infection (Fig. 8). Granular material is no longer observable and the cyst wall is composed of 4 sublayers which from the cyst cavity to the liver are: (1) finely granular and irregular thick; (2) electron-dense and regular; (3) pale and loose; (4) electron-dense and regular.

The middle and outer layers of the capsular-like coat show the same ultrastructural features as described for the 4 th month after infection.

Eight months after experimental infection, dead metacercariae were found in the hepatic parenchyma.

\section{Natural infections of Atherina Boyeri}

Histological observations of the liver of naturally infected silverside revealed a high level of infection by Labratrema minimus metacercariae (prevalence = $100 \%$, intensity $=47.3$, as shown in Fig. 9. In the homogenous parenchyma of the liver, necrosed hepatic cells define penetration zones of pre-encystment cercariae (Fig. 10).

In addition, metacercariae at various developmental stages (young, older: Maillard 1976), including some dead ones, can be observed (Fig. 11). As in Liza ramada, each cyst is surrounded by a lysed area and, in the hepatic parenchyma adjacent to the parasite, few hepatocytes are necrosed (Fig.12). Ultrastructurally, both the cyst wall and the capsular-like coat are rather similar to those described in L. ramada. The cyst wall is composed of a granular acellular material (Fig. 13). In

Figs. 5 to 8. Liza ramada experimentally infected by Labratrema minimus metacercariae. Electron micrographs of liver. Fig. 5 . Two months post infection: very flattened hepatic cells of the outer layer (ol) linked together by numerous desmosomes (D). A loose zone (lz) clearly separates the outer layer from the underlying hepatocytes $(\mathrm{H}) .(\times 12000)$. Figs. 6 \& 7 . Four months post infection: fully developed cyst wall $(\mathrm{Cw})$ and capsular-like coat $(\mathrm{ml}+$ ol). The cyst wall is divided into 2 sublayers (arrows). Note the presence of fibroblasts (Fi) in the outer layer (ol). Granular material (gm) is still detectable in the cyst cavity (Cc). (Fig. $6: \times 4500$, Fig. $7 \cdot \times 8000$ l. Fig. 8 . Seven months post infection: no more granular material can be seen. The cyst wall is now composed of 4 sublayers (arrows). $(\times 7500)$ 

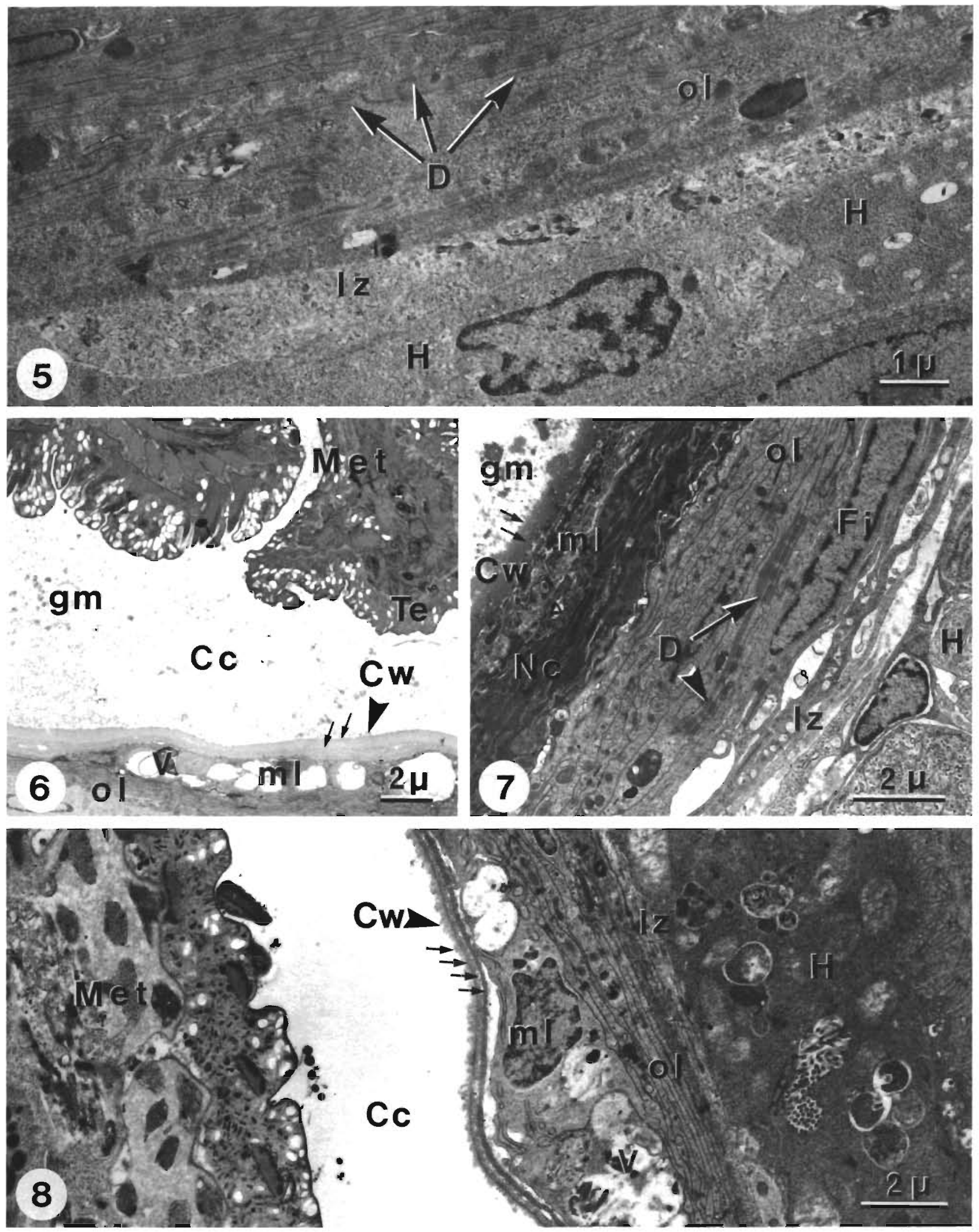

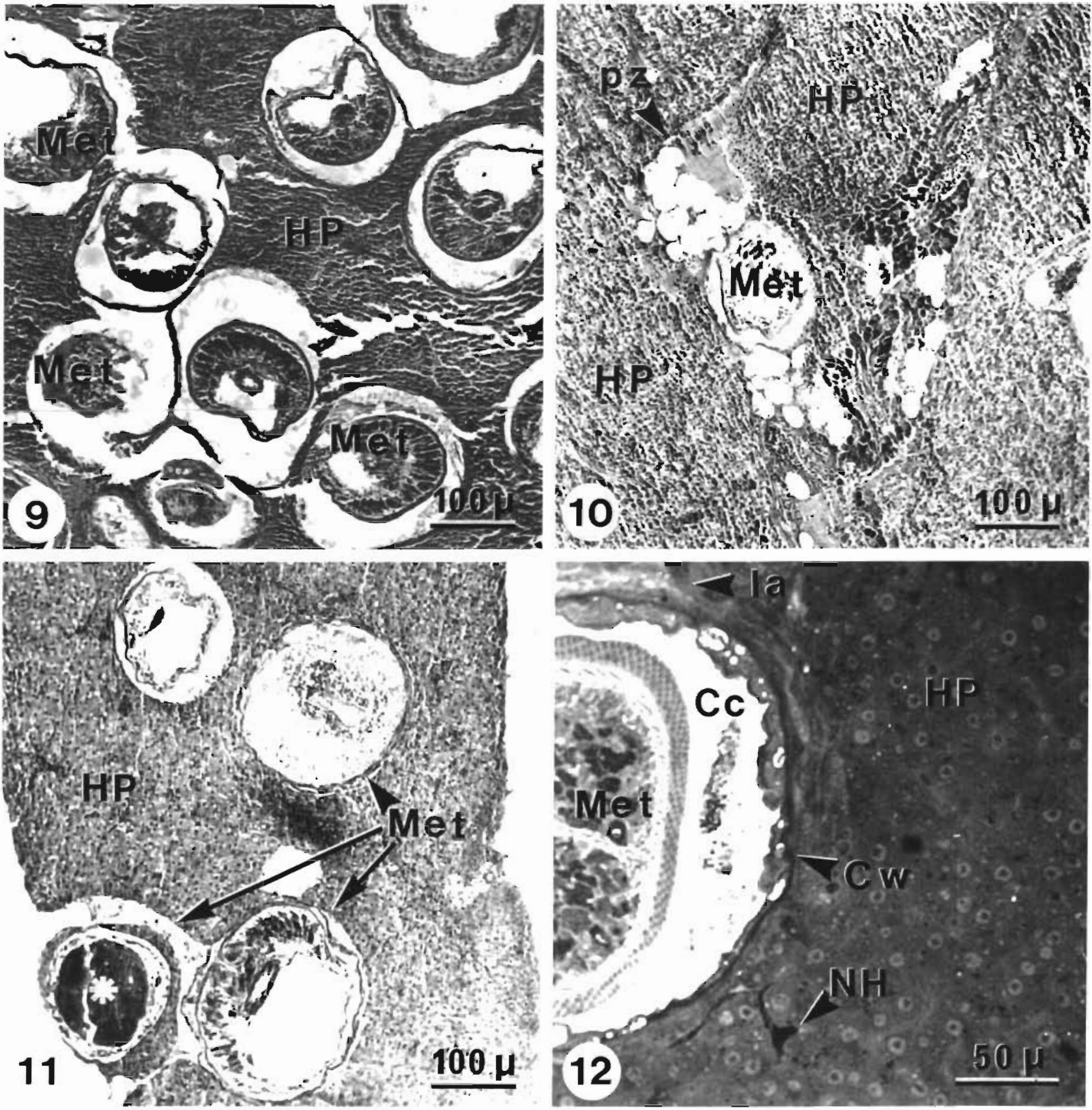

Figs. 9 to 12. Atherina boyeri naturally infected by Labratrema minimus metacercariae. Light micrographs of liver. Figs. 9 to 11. Paraffin sections stained with nuclear. fast red/picro-indigo carmine. Fig. 12. Semithin section, Richardson stained. Fig. 9. High level of infection by $L$. minimus metacercariae (Met) in the hepatic parenchyma (HP) of $A$. boyeri. ( $\times 128)$. Fig. 10. Penetration zones $(\mathrm{p} z)$ of cercariae before their encystment in the hepatic parenchyma (HP) in the shape of metacercariae (Met). ( $\times 128)$. Fig. 11. Metacercariae (Met) at various developmental stages, some of which are dead (*) in the hepatic parenchyma (HP) of $A$. boyeri. $(\times 128)$. Fig. 12. Cyst wall $(\mathrm{Cw})$ surrounded by lysed area (la). Note the presence of few necrosed hepatocytes (NH) in the hepatic parenchyma adjacent to the metacercaria (Met). ( $\times 320)$

the capsular-like coat, the very vacuolated middle layer is formed by lysed hepatocytes which have been disrupted during the penetration of the cercaria into the liver. The outer layer is composed of very compacted and flattened hepatocytes which are closely linked by desmosomes. In addition, a few fibroblasts and many collagenous fibres are located in this layer (Fig. 14).
In Atherina boveri and Liza ramada, some peculiarities related to the presence of metacercariae encysted side by side in the liver can be observed. The interface zone is then constituted only by the 2 cyst walls separated by a very narrow layer of necrosed cells, and the capsular-like coats are lacking (Fig. $15 \mathrm{a}, \mathrm{b})$. 

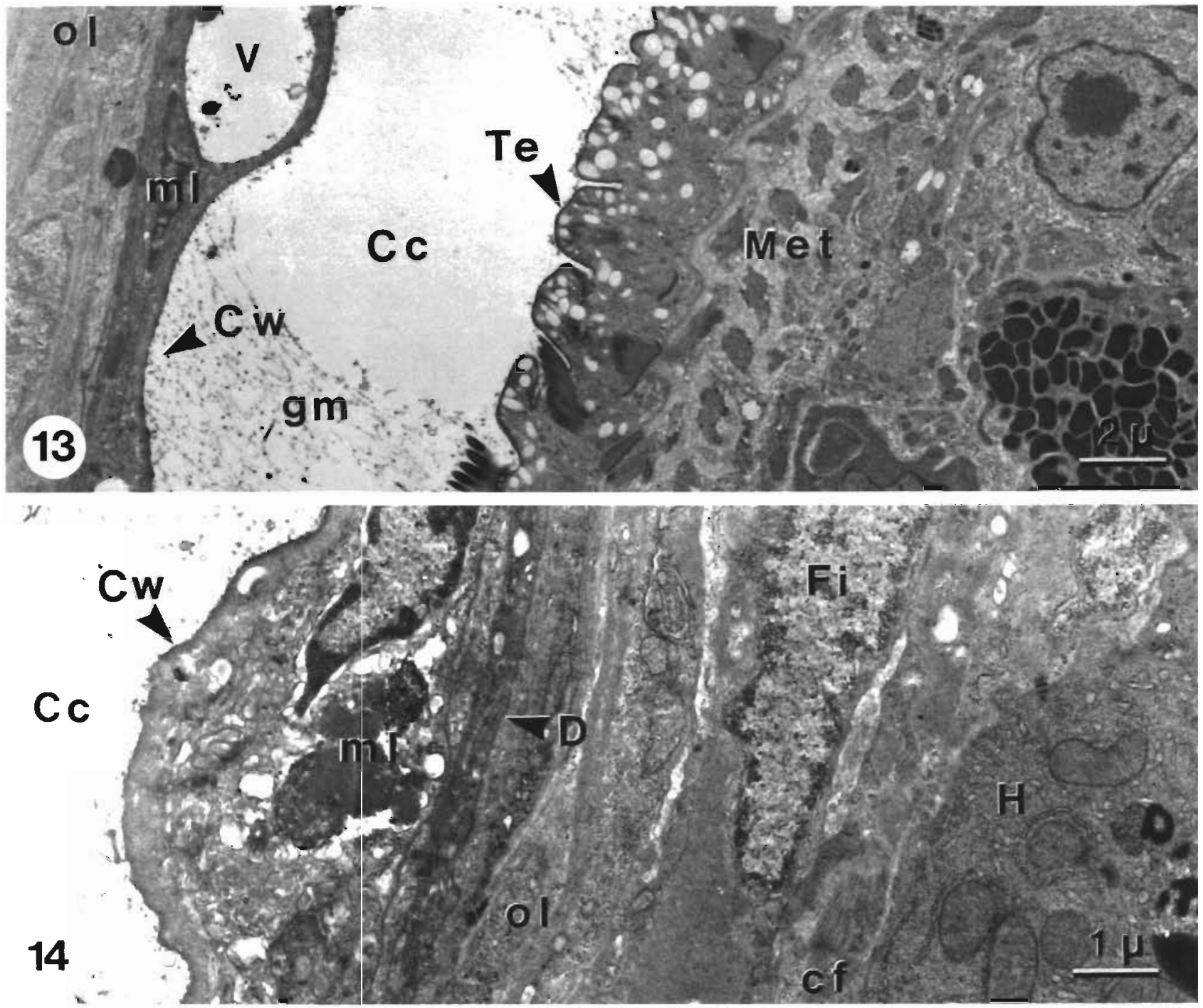

Figs. 13 \& 14. Atherina boyeri naturally infected by Labratrema minimus metacercariae. Electron micrographs of liver. The hostparasite interface consists of 3 distinct layers: a cyst wall $(\mathrm{Cw})$ and a middle layer $(\mathrm{ml})$ and an outer layer (ol) forming the capsularlike coat. Note the presence of collagenous fibres (cf) and fibroblasts (Fi) in the outer layer. Granular material ( $\mathrm{gm}$ ) is discernible in the cyst cavity (Cc). (Fig. 13: × 6000; Fig. 14: × 12000)

\section{DISCUSSION}

Our observations of Liza ramada juveniles, experimentally infected by Labratrema minimus, have revealed the formation and development of the metacercarial cyst wall and the capsular-like coat over a 7 mo period. The cyst wall, observable since the first day post infection, is composed of thin acellular granular material, scattered along the liver cells which are already compressed by the parasite settlement. The presence of small granules in the cyst cavity between the parasite and the hepatic parenchyma suggests that this material is probably secreted by the tegument of the parasite soon after its arrival at the encystment site. This interpretation is in accordance with the studies of Mitchell (1974) and Higgins et al. (1977). In addition, the latter showed that this deposit is formed by proteins and polysaccharides. The middle layer is composed of degenerative and even necrosed hepatocytes which are disrupted by the mechanical activity of the cercaria entering the liver, as suggested also by Higgins (1980). Maillard (1976) has shown that the cercaria utilize hepatocytes as a source of nutrition. The outer layer is constituted by flattened hepatocytes and the presence of some fibroblasts suggests a scarring process. Therefore, the cyst wall is composed of acellular granular material originating from the parasite, whereas both the middle and the outer layers of the capsular-like coat are made up of hepatic cells, thus demonstrating the mixed origin of this host-parasite interface. The hepatic origin of the capsular-like coat is corroborated by its absence between metacercariae encysted side by 

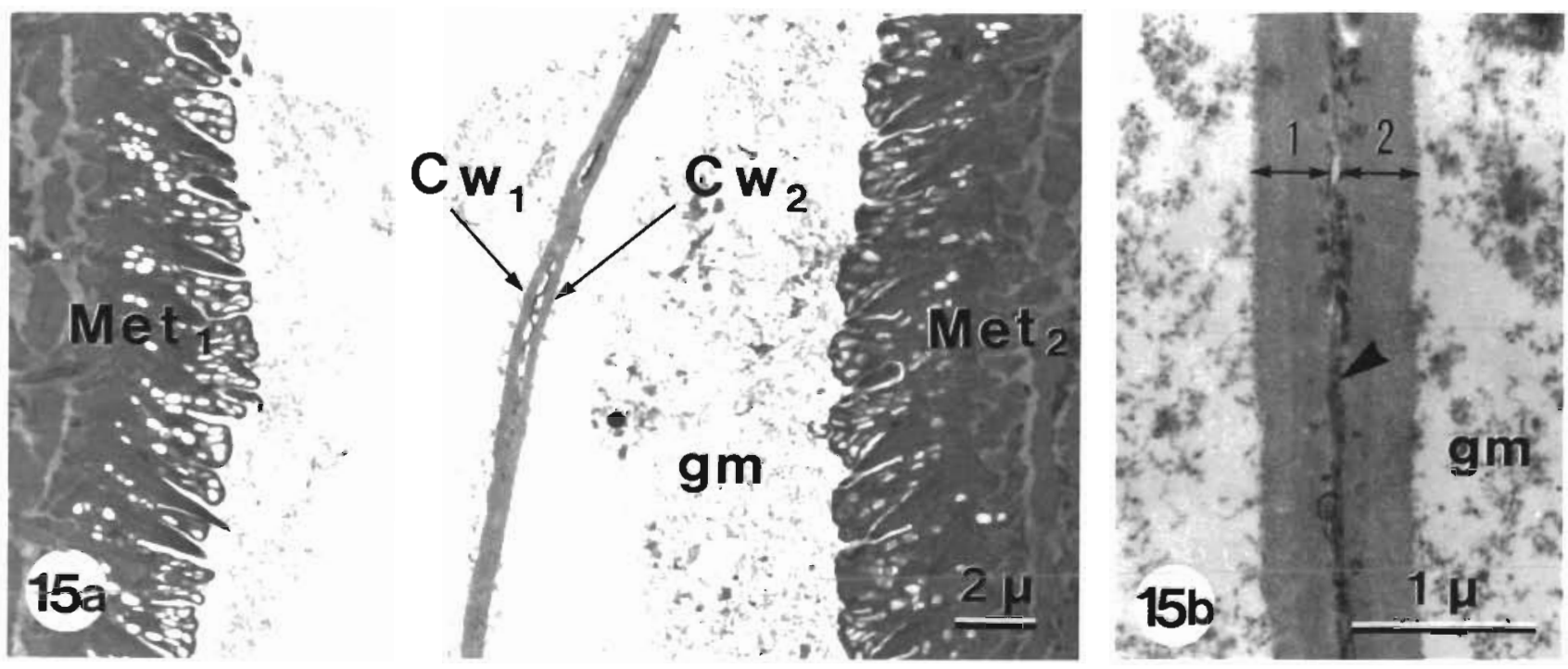

Fig. 15. Liza ramada experimentally infected by Labratrema minimus metacercariae. Electron micrographs of liver. (a) Two bracked cyst walls $\left(\mathrm{CW}_{1}\right.$ and $\mathrm{CW_{2 }}$ ) separating side by side encysted metacercariae $\left(\mathrm{Met}_{1}\right.$ and Met $\left._{2}\right)$. $(\times 4500)$. (b) Detail of the 2 bracked cyst walls $(1,2)$ separated only by a very narrow layer of necrosed cells (arrowhead). $(\times 20000)$

side. The narrow layer of necrosed cells probably corresponds to residual cells of the middle layer.

The 3 layers form sequentially from the initial to the outer. Their respective development in the pattern of thickness and compactness (constant deposit of granular material until the fourth month in the initial layer, increase in number and flatness of hepatocytes in the middle and outer layers) suggests a possible solidification of the host-parasite interface. Thus, the cyst wall shows electron-dense sublayers. Also, in the middle layer the degeneration of hepatocytes (electron-dense, devoid of cell structures) enables a greater compactness, and the numerous desmosomes in the outer layer streng then the capsular-like coat. This compactness is probably related to the increase in size of the parasite (from about $250 \mu \mathrm{m}$ for recently encysted metacercariae to 600 um for the older ones; Faliex 1984) applying pressure on the liver which is resistant. The settlement of the hostparasite interface appears to be a dynamic phenomenon gradually and continuously proceeding for 7 mo.

Two-thirds of the host-parasite interface is derived from host hepatic cells (middle and outer layer), which are completely integrated to this wall as noted by Mitchell (1974). That these no longer participate in a hepatic function is suggested by the presence of a loose zone which clearly separates the hepatic parenchyma from the capsular-like coat. These features can be explained as a protection of the parasite against a possible inflammatory reaction from the host. Thus, no immune cells were detected. This interpretation is in agreement with work by McQueen et al. (1973) and Mitchell (1974). In contrast, in flatfishes, Sommerville (1981) (Stephanochasmus baccatus) and Pulsford \&
Matthews (1984) (Rhipidocotyle johnstonei) found evidence for typical inflammatory reactions.

Lipid droplets observed at early stages $(1$ and $3 \mathrm{~d}$ post infection) in the parasite tegument could contribute to the establishment of the metacercarial tegument which undergoes reorganization from the cercarial to the metacercarial stage as described by Higgins (1980). The presence of lipid droplets in the cyst cavity suggests that this material could be released into this cavity either by removal or by disruption of the tegument which is thinned and stretched by such voluminous droplets. In tegument of Bucephalus haimeanus (Lacaze-Duthiers, 1854). Higgins (1980) described the appearance, from the 2 nd day post infection, of vesicles similar in size to the droplets we observed and released into the cyst cavity. However, in our observations at a later stage ( $15 \mathrm{~d}$ post infection), no more lipidic material was found either in the cyst cavity or in the cyst wall. What would be the fate of such lipid droplets?

Although few in number, lipid droplets observed within the initial layer (by the 3rd day post infection) could indicate a possible transfer either from the metacercaria to the liver or from the liver to the metacercaria. At this stage, the granular material is still loosely packed and would permit passage of such voluminous lipid droplets. It is possible that this material could originate from the host hepatocytes and constitute nutritive reserves for the parasite. Higgins (1979) showed such a passage for both particulate material and small molecules in solution. This supply of nutriments, added to the hepatic material already eaten by the cercaria during penetration into the liver, would contribute to the metacercaria growth. 
In naturally infected silverside, the cytological observations corroborated those on Liza ramada ( 3 characteristic layers constituting both the cyst wall and the capsular-like coat and a loose zone separating the hostparasite interface from the underlying hepatocytes). At the histological level, the observation of large numbers of metacercariae at various developmental stage indicates that the period of release of infecting cercariae is long. This opinion is corroborated by Maillard (1976), who showed that the infective period lasted from May to October. Thus, reinfections of the second intermediate hosts by Labratrema minimus cercariae in the natural environment during summer are possible. Some necrotic metacercariae died during encystment while others died on reaching their life expectancy. In the latter case, the lack of secretory activity of the metacercariae, detected in the seventh month, could correspond to the end of their life and to the beginning of a possible host reaction. Life expectancy in $L$. ramada is about 7 mo because at the 8 th month of the experimental study, most of the metacercariae were dead. These results are in accordance with those of Matthews (1973) who showed that in the liver of Pomatoschistus microps (Krøyer, 1838), the metacercariae of Bucephalus haimeanus survive $10 \mathrm{mo}$.

The experimental study carried out on Liza ramada showed the chronology of the formation and development of the host-parasite interface. The work on Atherina boyeri demonstrates the dynamic nature of the infection by Labratrema minimus as it really is in this second intermediate host in the field. Thus, a higher level of parasitic infection in $A$. boyeri than in $L$. ramada might be explained by habitat differences (e.g. whether more or less in the vicinity of Cerastoderma glaucum) and by differences in the thickness of their pectoral area through which cercariae enter the intermediate host.

Acknowledgements. The author expresses her gratitude to Prof. L. Euzet (Laboratoire de Parasitologie Comparée U.S.T.L. Montpellier) for his helpful advice and comments on the work.

\section{LITERATURE CITED}

Baturo, B. (1978). Larval bucephalosis in artificially heated lake of the Konin region. Poland. Acta Parasit. Pol. 25: 307-321

Biagianti, S., Maillard, C. (1986). Lésions ultrastructurales induites par un Trématode, Labratrema minimus (Stossich, 1887) (Bucephalidae) dans le foie de Liza ramada et Liza aurata (Mugilidae). In: Vivarès, C. P., Bonami, J. R., Jaspers, E. (eds.) Pathology in marine aquaculture. European Aquaculture Society, Spec. Pub. No. 9, Bredene, p. 153-170

Responsible Subject Editor: W. Körting, Hannover, Germany
Bruslé, S. (1983). Contribution to the sexuality of an hermaphroditic teleost, Serranus hepatus L. J. Fish Biol. 22: 283-292

Faliex, E. (1984). Parasitofaune et pathologie parasitaire de l'athérine Atherina boyeri (Risso, 1810). Diplome d'Etudes Appofondies, Université de Montpellier

Faliex, E., Biagianti, S. (1987). Metacercarial infection of marine fish by Labratrema minimus (Digenea, Bucephalidae): histo-cytological analysis of host-parasite relationship. Aquaculture 67: 229-232

Higgins, J. C. (1979). The role of the tegument of the metacercarial stage of Bucephalus haimeanus (Lacaze-Duthiers, 1854) in the absorption of particulate material and small molecules in solution. Parasitology 78: 99-106

Higgins, J. C. (1980). Formation of the cyst wall and related changes in the structure of the tegument of Bucephalus haimeanus during its metamorphosis from the cercarial to the metacercarial stage. Parasitology 81: 47-59

Higgins, J. C., Wright, D. E., Matthews, R. A. (1977). The ultrastructure and histochemistry of the cyst wall of Bucephalus haimeanus (Lacaze-Duthiers, 1854). Parasitology 75: 207-217

Jourdane, J. (1975). Ecologie du développement et de la transmission des Plathelminthes parasites de Soricidae Pyrénéens. Thèse Docteur ès Sciences, Université de Perpignan

McQueen, A., McKenzie, K., Roberts, R. J., Young, H. (1973). Studies on the skin of plaice (Pleuronectes platessa L.) III. The effect of temperature on the inflammatory response to the metacercariae of Cryptocotyle lingua (Creplin, 1825) (Digenea: Heterophyidae). J. Fish Biol. 5: 241-247

Maillard, C. (1976). Distomatoses de poissons en milieu lagunaire. Thèse Doctorat d'Etat, USTL Montpellier

Maillard, C., Lambert, A., Raibaut, A. (1980). Nouvelle forme de distomatoses larvaires. Etude d'un trématode pathogene pour les alevins de Daurade (Sparus aurata L. 1758) en écloserie. C. r. Acad. Sci. Paris 290: 535-538

Matthews, R. A. (1973). The life cycle of Bucephalus haimeanus (Lacaze-Duthiers, 1954) from Cardium edule L. Parasitology 67: 341-350

Mitchell, C. W. (1974). Ultrastructure of the metacercarial cyst of Posthodiplostomum minimum (Maccalum, 1921). J. Parasitol. 60: 67--74

Pulsford, A., Matthews, R. A. (1984). An ultrastructural study of the cellular response of the plaice, Pleuronectes platessa L., to Rhipidocotyle johnstonei nom. nov. (pro-Gasterostomum sp. Johnstone, 1905) Matthews, 1968 (Digenea: Bucephalidae). J. Fish Dis. 7: 3-14

Reynolds, E. S. (1963). The use of lead citrate at high $\mathrm{pH}$ as an electron opaque stain in electron microscopy. J. Biophys. Biochem. Cytol. 17: 208-212

Richardson, M. C., Jarett, L., Finke, E. H. (1960). Embedding in epoxy resin for ultrathin sectionning in electron microscopy. Stain. Technol. 35: 313-323

Sommerville, C. (1981). A comparative study of the tissue response to invasion and encystment by Stephanochasmus baccatus (Nicoll, 1907) (Digenea: Acanthocolpidae) in four species of flatfish. J. Fish Dis. 4: 53-68

Wallet, M. (1984). La bucéphalose larvaire à Bucephalus polymorphus (Baer, 1827) (Trematoda, Digenea). Biologie de la cercaire et aspects épidémiologiques dans le Sud-Est de la France. Thèse de Doctorat de 3ème cycle, USTL Montpellier

Manuscript first received: June 27, 1990

Revised version accepted: January 23, 1991 